\title{
Mesoderm: The Possible Key to the Organic Basis of Freud's Theories
}

\author{
Tina Lindhard \\ Department of Psychology (Consciousness Studies), International University of Professional Studies (IUPS), Maui, HI, USA \\ Email: t.lindhard@iups.edu
}

How to cite this paper: Lindhard, T. (2020). Mesoderm: The Possible Key to the Organic Basis of Freud's Theories. Psychology, 11, 1769-1793.

https://doi.org/10.4236/psych.2020.1111112

Received: October 27, 2020

Accepted: November 27, 2020

Published: November 30, 2020

Copyright ( 2020 by author(s) and Scientific Research Publishing Inc. This work is licensed under the Creative Commons Attribution International License (CC BY 4.0).

http://creativecommons.org/licenses/by/4.0/ (c) (i) Open Access

\begin{abstract}
The main body of the paper leads to the insight that there might be a correlational and/or developmental relationship between systems, layers, structures, levels of consciousness and Freud's model of the mind. It rests on three premises or postulates: 1) mesoderm might provide the key to the organic basis of Freud's topographical and structural models, both of which involve primary and secondary systems; 2) mesoderm is not a limiting skin, but a layer that simultaneously creates space and connects: 3 ) as it gives rise to the major structural components and organs of the inner body including the notochord (made of three-dimensional meso tissue) which underlies and promotes the development of the CNS made of neuroectoderm, mesoderm also involves primary and secondary aspects. In this paper, the possible links between these aspects are explored. As the activities, contents, and history related to the meso layer predate temporal reasoning associated with the prefrontal cortex, our contact with this deeper layer is either direct through feeling and sensation, which predate verbal thought, or indirect using free association and dreams. This perspective also throws light on Freud's agents of the psyche or soul, where the ego is the chief protagonist and whose actions and decisions are affected by unconscious processes. Resistance to accessing this inner "unconscious" layer is probably related to an early tendency in controlling the expression of emotional and instinctual behaviour.
\end{abstract}

\section{Keywords}

Freud, Mesoderm, Organic, Feeling, Unconscious, Ego, Prefrontal Cortex, Resistance, Emotions, Consciousness, Soul

\section{Introduction}

The thesis that there is possible correlational and/or developmental relationship 
between systems, layers, structures, levels of consciousness and Freud's model of the mind, was not contemplated at the beginning of my investigation. Rather, it grew out of my research as an intuitive insight as I began to gather the data presented in this paper where I started from an interdisciplinary perspective based mainly on embryogenesis. My initial investigation involved the consideration of a possible link between the middle of the three-germ layer that forms during our anatomical development, known as mesoderm, and the organic basis of Freud's topographic model of the mind and his structural model of the psyche. I refer to this hypothesis as "the meso hypothesis". The research centred around this suggestion but as it unfolded, the original hypothesis expanded to include a possible link between systems, layers, structures, and levels of consciousness and Freud's model. The paper follows the order of my explorations.

In a letter Freud wrote to Fleiss on the $22^{\text {nd }}$ September 1898, he says:

I am not at all in disagreement with you, not at all inclined to leave psychology hanging in the air without an organic base. But apart from this conviction, I do not know how to go on, neither theoretically nor therapeutically and therefore must behave as if only the psychological were under consideration. (in Masson, 1985, p. 326) ${ }^{1}$

Freud (1915a) felt there was a hiatus between his psychical system and its basis which could not be filled by psychologists "There is a hiatus here which at present cannot be filled, nor is it one of the tasks of psychology to fill it. Our psychical topography has for the present nothing to do with anatomy, it has reference not to do with anatomical locations but to regions in the mental apparatus, wherever they may be situated in the body..." (pp. 174-175) (emphasis added).

An organic basis for his models eluded Freud all his life, but considering our anatomical development gives rise to insights that might provide a solution to his dilemma. In the theory of the three germ layers, the inner layer is called mesoderm. However, according to van der Wal (2003/2014), it is not a derm but an inner layer which "creates space and connects at the same time" (p. 42). In brief, during a process known as gastrulation, the morphological structure of the human embryo is changed from a flat two-dimensional disc to a three-dimensional tri-laminar disc. Gastrulation "initiates at the primitive streak, a groove formed by internalizing cells along the posterior axial midline" (Houston, 2017, 6.6.3. Amniote Gastrulation) forming an inner layer known as mesoderm made up of cells which have migrated from the epiblast to the interior of the embryo, via the primitive streak. This process is called ingression (Kim, Xing, Yang et al., 2017) and it involves the transition of epithelial cells to mesenchymal cells, or "embryonic connective tissue", a ground substance comprising of a gel-like substance, which is part of mesoderm (Kierszenbaum \& Tres, 2015). Among other things mesoderm contributes to connective tissue, tendons, ligaments, bone car-

${ }^{1}$ Possible Links Between Freud's Theories and the Meso Layer (p. 7). 
tilage, muscle, blood vessels, lymphoid organs, pericardium, kidney and gonads, and, what is most important to us here, is the notochord (Openmd, n.d.; Hill, 2020a).

The notochord is one of the most important features in embryology. It is a mesodermal structure that not only provides structural support but marks the midline of the embryo. It will provide chemical and physical interactions with the dorsal lying ectoderm to specialize a portion of that ectoderm into neuroectoderm to derive the nervous system (Muhr \& Ackerman, 2020, Cellular, para. 3).

Not only does mesoderm create space and connect (van der Wal, 2003/2014), it acts in patterning the surrounding tissues including the outer layer known as ectoderm which forms the central nervous system including the neural part of the brain (Hill, 2020b, Introduction).

The neural plate folds, via induction from the notochord into the neural tube, which then becomes the neuroectoderm, which finally forms the CNS, namely the brain and spinal cord; the brain from cranial two-thirds of the segment and spinal cord from caudal one-third of the segment. (Elshazzly, Lopez, Reddy, \& Caban, 2020, Development, point 2)

Most articles on embryology encountered by this researcher support the hypothesis that the notochord (a mesodermal structure) induces the formation of the neural plate, which is the precursor of the CNS. This adds emphasis to the idea that the mesoderm is primary, and the neural system is secondary. This does not mean that all mesoderm structures develop before the initiation of neural development, but that mesoderm exists before the neural system starts to form. The primary organs and bodily tissue made of mesoderm tissue are all formed during fetal development even though they grow in size and their cells are being continuously replaced throughout our lives. The neural system, on the other hand, is made of neuroectoderm and continues to develop after birth when the prefrontal cortex shows significant developmental changes during the first year but only reaches full maturity in humans in young adulthood (Diamond, 2002). In keeping with Garn (1952), "growth" refers here to changes in magnitude or size of the organs, tissue thickness and overall size of the individual whereas "development" involves a change in complexity and proportions.

In Freud's topographic theory, the unconscious "operates via the primary process... (and) the perception consciousness system operates via the secondary process (Boag, 2017, abstract), and in Freud's structural theory, the id is associated with the primary unconscious system and the ego, which grows out of the id, and superego to the secondary system. As these two theories and the development of our inner mesoderm layer and the neural system made of neuroectoderm involve primary and secondary aspects, it is suggested they may be linked through correlation and/or developmentally in terms of the sequence in which they unfold. 
As background material, I also briefly outline Freud's theories and give a simple description of the development of our body during our embryological past. Then, among other things, I examine the relationship between Freud's key terms and our anatomical development, as well as exploring the "perception consciousness systems" used by the id and ego.

\section{Background}

\subsection{Philosophical Background}

Traditionally in the West, our knowledge about soul, mind, and consciousness has come to us through religion or philosophy. Philosophy, from the Western perspective, mainly involves the use of the thinking logical mind to contemplate and understand our nature. For Descartes, the non-physical indivisible mind was separate from the physical divisible body (Skirry, n.d.) and mind and soul were more or less the same entity. With the introduction of the concept of the unconscious in the late $19^{\text {th }}$ century by the German philosopher Schelling (Murray, 2004), the indivisible mind/soul of Descartes and its relationship with consciousness had to change. Freud's solution was two-fold: one in how he obtained knowledge about the mind, and two, the insights revealed about it based on the method he developed.

\subsection{Freud's Metaphysical Position}

There is a dispute regarding Freud's metaphysical position between the official translators of his work and (Bettelheim, 1984) which involves the translation of the German word Seele. For example, the German phrase Die Psychoanalyse ist ein Stuck der Seelenkunde der Psychologie translates into English as "Psychoanalysis is a part of psychology which is dedicated to the science of the soul", it has been translated in the Standard Edition, as "Psychoanalysis is a part of the mental science of psychology". "For Freud, psychology is the large discipline, part of which is the science of the soul; psychoanalysis is a special division of the latter discipline" (sect. X, para. 10). In Collins Dictionary (n.d.), the German word Seele is translated as soul, a feminine noun.

Even if Freud was interested mainly in the unconscious part of the mind, it does not mean that he denied the existence of the soul (psyche). On the contrary, his metaphysical position seems to suggest that the soul has a mind apparatus consisting of different parts or levels.

\subsection{Freud's Approach}

One of Freud's solutions in discovering more about concepts such as mind, consciousness, and soul was a shift in the way of acquiring knowledge about them that was also more in keeping with his time. He based his modus operandi on observations made during his clinical practice, which was consistent with his belief that psychological concepts were only useful if they illuminate human behaviour (Billig, 1999: p. 13; Freud, 1915b: p. 113). He felt this was a more scien- 
tific way of obtaining knowledge about the psyche, the mind, and human behaviour. Although he did not spell it out, we may presume he was comparing clinical observation to the method used by philosophers, which depends on logical thinking. As such, he would have been making a distinction between the two undertakings based on the different ways they accessed information.

\subsection{Freud's Early Model of the Mind}

His other solution was a model of the mind that arose out of his observations as a clinician when working with people with neurosis. According to his theory of repression on which he based the whole of his structure of psychoanalysis (Freud, 1914, 1923), factors that lie outside of conscious awareness determine mental states. This insight gave rise to his concept of the unconscious, which he saw as a reservoir of feelings, thoughts, repressed desires and urges, and memories (Freud, 1923, 1925).

\subsection{Freud's Structural Model of the Psyche}

As Freud's model of repression is dynamic, the next step in the development of Freud's ideas required addressing the different components of the psyche involved in the act of repression. In this model, which he launched in 1923, he talks about acting and interacting agents of the psyche. In brief, Freud's (1923) new structural model consisted of three elements: the id, which is subject to instinctual desires, a moralizing agent known as the super-ego, and the ego, a mediating agent in between. These concepts are psychological where tensions between the agents transform the behaviour of the person into a dynamic system.

\subsection{Freud's Energetic Component}

As Freud's model includes needs and desires, he required an energetic component. According to Tran The, Magistretti, \& Ansermet (2018), Freudian energetics is not based on vitalism but was influenced by a "physical model involving the principle of conservation of force in thermodynamics" (Conclusion, para 1). However, even if some of Freud's ideas were shaped by a physical model, it does not mean that this was the only model behind his energetics. Initially, he subsumed the different drives responsible for behaviour under Life instincts, where instincts lie on the frontier between physical and mental (Freud, 1905). Later he (Freud, 1920) revised his model and proposed they fall into one of two major classes: life instincts or death instincts. For Freud, our behaviour is influenced by these instincts, as well as the dynamic interplay between the id, ego, and superego.

\section{Our Anatomical Development}

\subsection{Blood-The First Functional Expression of Mesoderm in the Ectocyst or Placenta}

Blood is the first functional differentiation of the mesoderm in the ectocyst (placenta) and can be considered as a form of "liquid connective tissue" (Hill, 2020b, 
Introduction) which links the mesoderm of the ectocyst with the mesoderm of the endocyst (germinal disc) during embryonic development. Through capillaries, blood brings nutrients and oxygen from the metabolic periphery of the trophoblast, or extra-embryonic mesoderm to the bi-laminar germinal disc via the body stalk. It then runs primarily along the outer "flanks" of the germinal disk towards the cranial end of the embryo. At the central point of the cranial end of the germinal disc, it comes to a halt and then flows back to the periphery through other capillaries. Van der Wal calls this point the "centripetal junction of blood vessels" and at the point of reversal, flow "comes to a standstill, turns about, and takes on a rhythmical character (which) is the first indication of the origin of the heart" (van der Wal, 2003/2014: p. 44). According to Villavicencio (2010), the rhythmical contractions of the fetal heart occur before the conduction system is established. After the genesis of heart area, many developmental processes are now observed within the germinal disk, the most essential of these is the start of inward growth at the caudal end of the embryo (van der Wal, 2003/2014).

\subsection{The "Three Germ Layers"}

The theory of the three germ layers was first put forward in 1817 by Pander, a doctoral student in Germany. In triploblastic organisms, including humans, "the endoderm and ectoderm interact to produce a third germ layer, called mesoderm" (MacCord, 2013, para. 1), a process known as gastrulation. The inner ectoderm layer forms the lining of the organs, vessels, and gut, and the outer layer, known as ectoderm meaning outer skin, forms into the skin, hair, nails, and the nervous system (Gilbert, 2010).

\subsection{Gastrulation}

As described earlier, near the end of the $3^{\text {rd }}$ week an intermediate layer appears between the ectoderm and the endoderm, namely the intra-embryonic mesoderm.

It makes its way into the germinal disk, by growing inward, starting from the primitive groove, thereby forming a three-dimensional entity with "real inner content" from which the impulse to "forming organs arises" (van der Wal, 2003/ 2014: p. 44).

The embryologist van der Wal (2003/2014) points out that mesoderm is not a derm or limiting skin but a layer that simultaneously "creates space and connects". It gives rise to an "inner tissue.... with a third dimension". In keeping with Blechschmidt, he feels the term mesoderm gives rise to confusion in perception (p. 42). This developmental phase of the body involves changing from a flat two-dimensional disc to a three-dimensional tri-laminar germinal disc.

Mesenchyme, derived mostly from the mesoderm layer, is a tissue comprised of loose cells embedded in a mesh of proteins and fluid, allows for easy migration of cells due to its loose fluid nature. "It plays a crucial role in the origin and development of morphological structures during the embryonic and fetal stages of animal life" (MacCord, 2012, para. 3). In all vertebrates including humans, 
mesoderm gives rise to the voluntary and involuntary muscles that make up the great muscle masses "which underlie all of our work, actions and behaviour, and the involuntary muscles, which make up the walls of all of our organs such as heart and blood vessels, respiratory and gastrointestinal systems, and our bones" (Course Hero, n.d., Topic 02: Neuroanatomy). "Connective tissue, cartilage, bone (except the maxillofacial bones), notochord, blood, bone marrow, lymphoid tissue, and to the epithelial (surface, or lining, tissues) of blood vessels, lymphatic vessels, body cavities, kidneys, ureters, gonads (sex organs), genital ducts, adrenal cortex, and certain other tissues" are also all derived from mesoderm tissue (Editors of Encyclopaedia Britannica, n.d.).

\subsection{The Notochord and the Development of the CNS}

The notochord is one of the most important features in embryology. It is a mesodermal structure that not only provides structural support but marks the midline of the embryo. It will provide chemical and physical interactions with the dorsal lying ectoderm to specialize a portion of that ectoderm into neuroectoderm to derive the nervous system (Muhr \& Ackerman, 2020, Cellular, para. 3).

This long cylindrical structure acts in patterning the surrounding tissues including the outer layer known as ectoderm, out of which the central nervous system forms (DeSesso \& Williams, 2018; Hill, 2020a, Introduction; Grow, 2018; Coad, Pedley, \& Dunstall, 2011; Stemple, 2005).

\subsection{Delamination or Folding}

During the $3^{\text {rd }}$, but primarily the $4^{\text {th }}$ week, a process, known as folding or delamination, starts to occur. This transforms the three-dimensional embryo into the form of a cylinder. At the same time, the heart at the cranial end of the embryo, begins its descent (Richtsmeier, 1999), allowing the brain primordium to take its place at the top cranial end of the embryo. The caudal end also raises ventrally, which gives rise to the umbilical cord. This curving process creates an inner world in which the organs develop.

\subsection{CNS}

The formation of neuroectoderm (or neural tube epithelium) out of the ectoderm layer is the first step in the development of the nervous system (Schoenwolf, Bleyl, Brauer, \& Francis-West, 2015: p. 77). The neural plate starts to form on day $18 / 19$, and in turn, gives rise to the neural tube. This tube is a visible dorsal line that curves inwards giving rise to the neural fold, the sides of which finally meet to form the neural tube that lies beneath the ectoderm layer. This process is complex and not yet entirely clear and de Bree, de Bakker, \& Oostra (2018) suggest that the notochordal process and neural tube development, might be intimately related. This is supported by the suggestion "the neural plate develops in step with the genesis of the notochord" (Human Embryology, n.d. Module Embryonic disc, 7.2 para. 3). 
Starting on about day 25, the anterior end of the neural tube develops into the brain, whereas the posterior portion becomes the spinal cord (Champney, 2016). This basic arrangement of tissue structure eventually develops into the CNS and the brain comprising of neural ectoderm.

\subsubsection{The Development of the Brain}

It is possible to distinguish three bulges at the anterior end of the neural tube when the neural groove is still completely open. Then, on day 29 , when the head has become larger than the cardiac loop, on close examination the "three brain vesicles or neuromeres can be identified: the prosencephalon (forebrain), the mesencephalon (midbrain) and the rhombencephalon (hindbrain)" (Moscoso, 2009: p. 15). The primary vesicles differentiate into five secondary vesicles, which are the basis of the structure of the fully developed adult brain (OpenStax, n.d.).

\subsubsection{Prefrontal Cortex}

What is of interest is the prosencephalon or forebrain. Phylogenetically and ontologically the cortex of the frontal lobe, also referred to as the prefrontal cortex (PFC), develops late (Fuster, 2002). Although this region shows significant developmental changes in the first year of life, it is only in young adulthood that it reaches full maturity in humans (Diamond, 2002) where it occupies one-quarter of the entire cerebral cortex.

The cognitive functions of the frontal lobe, and more particularly the PFC, have to be understood in the context of its evolutionary origin via the adaptation of the organism to its environment and its relation to other cortices (Fuster, 2013). This is contrary to the idea that the cortex can be subdivided into modules related to specific functioning; a hypothesis based on brain legions which has not been supported by electrical recording and imaging neither has it been "unambiguously demonstrated" (Fuster, 2013: p. 20). From an evolutionary perspective, premotor and prefrontal executive functions are the building blocks for later goal-directed, higher functioning by the PFC, which involves the "temporal organization of behaviour, speech, and reasoning". These functions are supported by at least three other cognitive functions: "active short-term memory (working memory), preparatory action set, and control of interference” (Fuster, 2009: p. 905). The expression and control of emotional and instinctual behaviours (subsumed under the control of interference) are related to the ventromedial areas of the prefrontal cortex, which, considering other prefrontal areas, develop relatively early (Fuster, 2002, abstract). In Fuster's model, brain development builds on prior functions, and skills, including the control of emotional and instinctual behaviours, and is continuously being updated according to the requirements of the interaction of the organism with the environment.

\section{The Relationship between Freud's Models and Our Anatomical Development}

Freud's ideas and models do not come in a neat coherent packet but appear 
more like a "historical account of an adventurous explorer developing a system of concepts that changed and grew continuously and unevenly over a half-century of creative effort (Madison, 1956: p. 75). Nevertheless, Freud's core understanding, which involves the division of the psychical (mind) into conscious and unconscious systems is the heart from which all his other insights arise. It appears what changed was the perspective from which he was looking at the clinal evidence on which his theories rest.

Comparing Freud's two models with the anatomical development of the body based on the theory of the three germ layers provides us with a new perspective from which we can contemplate and maybe make sense of some of Freud's explorations.

In resumé

- Freud's topographic theory of mind, which he first introduced in 1900, proposes we have a mental apparatus consisting of three mental systems that can be understood descriptively, systemically, and dynamically: the unconscious (Ucs), the preconscious (Pcs.), and conscious (Cs.) where "the Ucs operates via the primary process... (and) the Pcs./Cs. systems operate via the secondary process" (Boag, 2017, abstract).

- In 1923, Freud introduced a structural system involving different agents of the psyche, which he called the id, ego, and superego. In this model, the id, as an agent of the psyche, is linked to the primary unconscious system and the ego or das Ich to consciousness, which operates via the secondary process.

- Sequentially, the mesoderm layer, which gives rise to the notochord and the major organs and structural components of the body and prompts the development of the neural system, is primary, and the neural system made of neuroectoderm is secondary.

As all three perspectives involve primary and secondary aspects, it seems that they may be connected through correlation and/or developmentally in terms of the sequence in which they unfold.

\subsection{The Spatial and Functional Connection of the Surface Mental Apparatus}

The mental apparatus of Freud can be looked at descriptively, systemically, and dynamically (Boag, 2014, 2017). One can also look at it spatially in terms of function, where mind is part of consciousness. Freud (1923) ascribed this to the "surface of the mental apparatus", also in the sense of "anatomical dissection" (p. 7). The PFC (cortex of the frontal lobe) is the surface of the mental apparatus, also anatomically. It, and the functions associated with it, develop late and only reaches full maturity in young adults. These functions operate via the secondary process.

\subsection{The Prefrontal Cortex, Thoughts, and the Conscious and Preconscious Mind}

For Freud (1923), "being consciousness, is in the first place a descriptive term, 
resting on the most immediate and certain character" (3). He was interested in distinguishing between conscious ideas or thoughts and ideas that do not stay in our consciousness for long before they become "unconscious". The cerebral region associated with higher brain functions is linked with "the temporal organization of behaviour, speech, and reasoning" (Fuster 2009: p. 905) and executive function (Domenech \& Koechlin, 2015). Freud (1923) talks about ideas that are transitory but can under certain conditions become conscious again. As such they are "latent", but if we used the term "unconscious", we would also be correct. Descriptively, we can talk of having a "latent unconsciousness" (p. 3).

This distinction of Freud's also has a relationship with neural functioning where the prefrontal cortex, among other things, is connected to short term memory (Fuster, 2009) and working memory, where a limited capacity of memory resource is allocated to each component of a task-dependent on its requirements (Funahashi, 2017). Freud (1923) talks about word-presentations as being residues of memories which were perceptions at one time and "like all mnemic residues, they can become conscious again (p. 7).

\subsection{The Connection between the Unconscious Mind and the Mesoderm Layer}

Whereas the conscious and preconscious mind is linked with the neural system, here it is suggested that the unconscious mind is connected to the meso layer. As our conscious thinking mind associated with the pre-frontal cortex develops later than the functions and processes related to the contents of the mesoderm later, we cannot contact this inner layer and its contents directly using our thinking faculty. However, we can experience the processes of this inner layer through feelings and sensations, which predate verbal thought and also indirectly using various methods such as dreams (Freud, 1900) and free association, a method Freud developed between 1892 and 1898 (Jones, n.d.).

\subsubsection{Feelings and Sensations}

Freud (1923) admitted he knew very little about feelings and sensations except they come into consciousness directly and not through a preconscious process; they are either conscious or unconscious. He also recognized that internal perceptions are "more primordial, more elementary, than perceptions arising externally" (8) and "yield sensations of processes arising in the most diverse and deepest strata of the mental apparatus" (p. 8). They have different origins and can have different or even opposite qualities.

Although we have not developed an ego or a social definition of ourselves during the early part of our existence, it does not mean that we, or the id part of our psyche, are not aware of what is happening. A baby is very much aware of its needs, even though it has not developed its verbal ability to describe them.

Although Freud (1923) does not address the nature of the perceptual system used by the id, he muses if we are right in delegating "the whole of consciousness to the single superficial system Pcps-Cs” (8). As many neuroscientists feel con- 
sciousness is a product of the brain, this question is as relevant today as it was in Freud's time.

\section{1) Touch as the primary"sense"}

A possible answer to Freud's question regarding perception involves touch, which probably is the first sense to develop (Fulkerson, 2015) in the embryo, and, unlike the other senses, it appears to be multisensory. Touch is more than perceptual awareness constituted by signals made available through the receptors in our skin, but is also associated with bodily awareness (Fulkerson, 2014, 2015).

The superficial part, known as cutaneous touch, is entirely mediated through the skin (ectoderm) and depends on our subjective awareness as a secondary quality. It is connected with experiences like hot and cold (thermal awareness) and pain. The registration of pain, for example, is dependent on receptors in the skin connecting with their neural connections in the cortex: a "system (that) isn't developed until the third trimester of pregnancy" (Davis in Miller, 2016, Fetal development, para 1).

The other aspect of touch is known as "haptic" touch. It is connected with movement and "involves many essential receptors that are located in the muscles, joints, and tendons, and not in the skin at all" (Fulkerson, 2015, 2, Is Touch Multisensory? para. 5). As muscles, joints, and tendons are made from pre-somatic mesoderm (Kardon, 2011), haptic touch maybe linked to the primary mesoderm layer. As this inner layer is a process unfolding in time, it is in constant movement. As the organs and muscular structures develop before the third trimester, body-based awareness might be earlier than the development of cutaneous touch. The possible connection of touch and body-based awareness with the meso layer warrants further investigation.

This suggests we may initially be "feeling beings". This is consistent with embodied cognitive science that suggests cognition depends on aspects of the agent's body, other than the brain, and challenges the prevailing dominant view of the mind... as well as undermining the idea that "the mind is identical to, or even realized in the brain" (Wilson \& Foglia, 2015, para. 4).

\section{2) The senses and the vestigial senses}

If bodily awareness based on feeling is our primary awareness and is direct, information about the world outside which we receive through our senses is of a different order. Freud identifies the role of perception in the development of the ego-personality. This formation possibly comes about through a shift from the id's relation to inner space involving direct awareness, to its relationship with outer space, which involves the senses. In this shift, the ego grows out of the id (Freud, 1923). Our senses give us information about objects where both sensation and perception involve the "superficial system Pcps-Cs" (8). Nevertheless, Freud (1923) also opens the possibility that the Pcs might have a "special sensory source" such as visual residues, and "verbal residues being derived from auditory perceptions" (8). The visual, as a way of acquiring or accessing information, plays a special role in dreams and Freud suggests it may "be nearer to the un- 
conscious than does thinking in words, and it is unquestionably older than the latter both ontologically and phylogenetically. (p. 8). These observations suggest that the other senses might have a vestigial component, which, like touch, has a direct connection to the meso layer.

\subsubsection{The Pleasure/Unpleasure Principle}

Feelings are direct, they "are either conscious or unconscious" (Freud, 1923: p. 9). This applies to bodily functions of which we are unaware until a need or desire arises. In Freud's (1920) theory, the pleasure/unpleasure principle governs these primary processes. As he did not have an organic basis for his theory, he was only able to address the force that gives rise to the needs/drives and the psychic apparatus that seeks to discharge it. As already described, the mesoderm layer gives rise to the major structural components of the body through which the dynamics and functions of the physical body take place, including the sexual. When activated, these needs are felt as unpleasurable, which motivates us to action to reduce them. Initially, Freud talked of force giving rise to these needs as the "unpleasure principle" (Freud, 1900), but later, in 1911, changed it to the pleasure/unpleasure principle. For him, this principle governs primary processes such as hunger, thirst, and the sexual drive, whereas the psychic apparatus seeks to discharge it. Freud, in his earlier works (Freud, 1911; Freud, 1915b), talks of the pleasure ego and reality ego where drives submit to the influence of the reality principle. However, "the sexual drive remains longer under the domination of the pleasure principle, a fact that is significant for mental development and neurosis in particular" (Hartmann, 1956: p. 31).

Insights regarding pleasurable and unpleasurable forces as motivating human behaviour are not exclusive to Freud, and go back in time, with philosophers such as Bentham saying that "nature has put man under the control of two sovereign masters, pain and pleasure" (Hartmann, 1956: p. 31). This principle may be associated with the dynamic interplay of the various functions of the organs that make up the meso layer as part of the biological play of nature. In Biology, they talk of anabolism, metabolism, and catabolism.

Freud's concept of the unconscious goes beyond bodily functions and their discharge. His ideas about the unconscious are intimately connected to his theory of repression. He (1923) also reminds us that although "all that is repressed, is unconscious but not all that Ucs. is repressed" (p. 6). He recognized clearly that the unconscious he was interested in was different from thoughts that are pre-latent and in contrast to surface consciousness, the unconscious is carried out in an unknown material (Freud, 1923). This is consistent with the hypothesis presented here where the components of the meso layer involved in primary functions, are made from three-dimensional mesoderm tissue, whereas our thinking ability is linked to the brain made from neuroectoderm.

\subsubsection{Memory and the Mesoderm Layer}

Although Freud (1923) suggests that memory of occurrences "merge into the 
id... (and) become part of it" (p. 10), he does not explain this further. This may mean that the id holds memories, or the whatever might be linked to the id, holds the memories. Freud's topographical model supports the first suggestion, although he never clarified the location of the unconscious mind. The second hypothesis permits a fresh look that does not exclude Freud's hypothesis but suggests memory might also be held in the mesoderm layer.

Starting with Tulving (1972), certain neuropsychologists make a distinction between semantic and episodic memory; the first is related to general knowledge and the latter specific events. Although these may also be neurologically interdependent (Greenberg and Verfaellie, 2010), it does not mean that episodic memory is held only in the neurological layer. We may hold unreleased memories of an emotional nature in our body, including the muscles. Support for somatic memory comes from heart-transplant patients (Pearsall, Schwartz, \& Russek, 2005; Skofield, 2012), somatic-based meditation methods such as Prayer of the Heart (Louchakova, 2004, 2005, 2007) and the Intuitive Meditation method (Lindhard, 2016, 2017, 2018); body-based therapies like Rolfing (Jacobson, 2011; Marsh, 2015), and psychiatry (van der Kolk, 1994).

Our body may be seen as an unfolding process consisting of an inner and an outer layer, which is interconnected. This implies that memory stored in the "inner" body related to the mesoderm layer might also be reflected in the nervous system. The autonomic nervous system (ANS) is essential for maintaining cardiovascular and respiratory homeostasis, which are especially critical in the new-born. At birth, adverse environmental and physiologic influences can seriously affect the maturing ANS as critical connections are formed between it and the limbic system which integrates psychological and body responses. Simplistically, the sympathetic component of the ANS is "responsible for the well-known "fight-or-flight" response activated from a sense of danger or elevated stress, and the parasympathetic nervous system, involved in vegetative functions, and moderating sympathetic activity" (Mulkey \& du Plessis, 2019: p. 121). According to Porges's Polyvagal Theory (Porges, 2001, 2009), impairment of vagal balance may be behind a broad range of neuropsychiatric disorders and also affect social responses (Mulkey \& du Plessis, 2019, Abstract).

In Freud's (1895/1966) letter no 52 to Fleiss, he talks of the stratification of our psychical mechanism as a process and how memory traces can be subject to re-arrangement under new circumstances. In the same letter, Freud mentions that he felt that the neurons were the vehicles for carrying information from the periphery to the cortex. Freud, however, did not go into the nature of the periphery, nor did he consider that it too might carry memory and that tensions and/or contractions in the components of the meso layer might be reflected in the CNS, including vagal balance. From the perspective presented here, relaxation of old muscular tensions involved in early memories may affect the nervous system and improve vagal tone.

Damasio (1999) points out how feelings as a bodily response to what is going 
on, influences decision making, and cognition. It is the outcome of these body responses to "conscious experience ...what changes brain patterns so that subsequence experience and intended action become modified (Pribram, 2005: p. 176). Pribram \& Melges (1969) suggest the higher frequency oscillations produced by the brain are a reflection of the conscious perception and labelling of feelings and emotions of the low-frequency oscillations produced by the heart in the form of afferent neural, hormonal and electrical changing patterns (McCraty, 2003). This could work in both directions as it is equally possible that our thoughts, or a change in them, can affect the components of the meso layer (Lindhard, 2015). This is supported by the findings of Nummenmaa et al. (2013) which suggest that each emotion affects our body in a specific topographical way depending on the emotional word pronounced. For Freud (1923) thought processes represent "displacements of mental energy... which (when unconscious) is carried out on some material which remains unknown" (7), which suggests that our thoughts, even the ones we are repressing, might affect the mesoderm layer and possibly other material entities as well.

\section{The Agents of the Psyche/Soul and Repression}

For Freud, the tensions between the agents of the psyche transform the decisions and behaviour of the person into a dynamic psychological system, where the ego is the chief protagonist.

\subsection{The Id and the Development of the Ego}

The id as an agent of the soul of the newborn is subject to the primary processes, and, as a psychic agent, it seeks to discharge them. According to the hypothesis presented, these primary processes might be directly linked to the bodily dynamics and functions of the components of the mesoderm layer, including the sexual.

The ego (Ich) grows out of the id (Es) and its "lower portion merges into it" (Freud, 1923: p. 10). As such, his structural model also has a developmental aspect. The ego can be seen as coming into being slowly through the contact of the baby with the exterior environment and other beings through his or her perceptual system, which is connected with the neural system. "For the ego, perception plays the part which in the id falls to instinct" (Freud, 1923: p. 10). The formation of the ego seems to involve the shift from the id's relation to inner space through direct awareness to the ego's involvement with outer space through the senses. As the senses start to function in the uterus, it is possible these early agents of the psyche also exist in some form while we are still a fetus.

The ego or the I (das Ich) is a "coherent organization of mental processes... and controls the approaches to motility-that is the discharge of excitations in the external world" (Freud, 1923: p. 5). Consciousness, for Freud, is attached to the ego or the I, who also "supervises all its own constituent processes through repressing what can come into conscious awareness but also "from other forms of effectiveness of activity" (p.5). 


\subsubsection{The "Social Ego"}

Developmentally, the next stage of the individual is the ego which "is first and foremost a bodily ego" where "the scene of the activity of the lower passions is in the unconscious" even though our "social feelings rest on the identification with other people, on the basis of the same ego ideal" (Freud, 1923: p. 18). In this latter sense, maybe we can talk about the development of a "social ego". This first statement of Freud's can be understood in the light of our anatomical development where the inner meso layer is our primary reality, but through increasing contact with the outside world and other beings via our senses, we start developing the superficial system Pcps-Cs where early premotor and prefrontal executive functions provide the building blocks for later higher functioning by the PFC (Fuster, 2009). As already discussed, substantial changes in the PFC are detected in the first year, but it is only when we reach young adulthood that it reaches maturity. Based on our ideas about ourselves, which according to Freud (1923) is related to our ego-ideal (18), we slowly develop what we can call a "social ego-personality"

\subsubsection{The Superego}

Freud also identified a moralizing aspect of the psyche, which he called "the ego ideal or superego" (Freud 1923: p. 12). The superego reflects both the parental ideal and cultural norms (Freud, 1933) and is therefore not connected directly with our meso hypothesis, except in the sense of influencing what aspects of the overall field are allowed to come into conscious awareness and deciding what needs to be repressed. In the latter sense, it operates hand in glove with the ego in controlling instincts, where the ego is the agent of perception and the ego ideal a "form of conscience,... (which exercises) moral censorship" (Freud, 1923: p. 18).

\subsection{Repression}

According to psychoanalytic theory, certain ideas and memories cannot become conscious as there is a force that opposes them. Psychoanalysis involves removing this resisting force so the repressed ideas can come into conscious awareness again (Freud, 1923). Repression by the ego might be reflected in the ventromedial area of the prefrontal cortex which develops relatively early when considering other areas of the PFC and is involved in controlling the expression of emotional and instinctual behaviours (subsumed under the control of interference). This suggests repression and resistance might involve differences between primary and secondary layers, where the repressed material belongs to the primary mesoderm layer, and the resisting agent our social ego-personality or ego ideal, both of which are projections of the neural system.

When looking at the system from an energetic point of view, the art and craft of psychoanalysis is restoring balance through "rebalancing and releasing energy flow disturbed or blocked by disease and illness" (Edwards \& Edwards, 2010, Abstract).

\section{Discussion}

The hypothesis presented may throw new light on Freud's models and ideas, 
but it also may transform them as, based on this hypothesis, it is easy to read into his work things that are possibly not there. His ideas themselves do not come in a neat tidy package (Madison, 1956), which also makes any analysis difficult. But the biggest problem is the possible errors in the translation of his key concepts, such as Seele and das Ich. In An Outline of Psychoanalysis, written in 1938 and published in 1940, there is a phrase "Von dem, was wir unsere Psyche (Seelenleben) nennen, ist uns zweierlei bekannt" (13). In the Standard Edition, this is translated as "We know two kinds of things about what we call our psyche (or mental life)," whereas, according to Bettelheim (1984), the correct translation is "We know two kinds of things about what we call our psyche (the life of the soul)" (Section X, para. 9). Freud "repeatedly stated that the I is only one aspect of our psyche, or soul, and separated it from the two others, the it and the above-I" (para 9). In German, he used the term das Es (lit. the "It"), das Ich (lit. the "I"), and das Über-Ich (lit. the "Over-I" or "Upper-I") By translating the das Ich as ego, we miss the dimension of Freud's insights on us as an "I". Mostly when we say "I", we are referring primarily to the conscious, rational aspects of our self, without taking into account of how each of us is influenced by "irrational, unconscious aspects of our mind" (Bettelheim, 1984, section VIII, para. 11). It is these aspects Freud sought to understand.

For Freud, the mind has conscious, preconscious, and unconscious facets, and the incarnating psyche or soul has or operates through different agents. Freud introduces a duality, but in his, the ego-personality or I (as an aspect of the soul) is "first and foremost a bodily ego" (Freud 1923: p. 12) and grows out of the id, another agent of the soul. This duality is very different from the philosophical opinion of Descartes where the soul/mind was seen as virtually the same thing and separate from the body.

His system is also different from that of Plato, which also has three parts, the rational, the spiritual (soul), and the desiderative. As desires are not only limited to the latter part, Segalerba (2019), refers to Plato's desiderative as "appetitive" (20). In Freud's system, the id has a natural desire to satisfy bodily needs, but it also has other desires. These are not under discussion here as they are purely psychological. Nevertheless, we must also bear in mind that since Freud's time, research has shown that primates also have other basic needs, which include timely attention, affect, feeling, warmth, and contact, as demonstrated by Harlow's experiments with monkeys (APS, 2018). This implies we might also have a natural desire to satisfy these needs as well.

A major difference between Freud's system and that of Plato is that in Freud's, the soul has different agents and it is the interplay of the three aspects of the soul which make the I (das Ich) not always behave in rational ways.

Freud's system seems to imply a developmental aspect where the bodily ego grows out of the id and into an ego whose identification with other people is based on the "same ego ideal" (Freud, 1923: p. 18). In this sense, we can maybe 
talk about the development of a "social ego", who nevertheless is still subject to the basic needs. These are contrasting aspects of the ego or I, one is socially conditioned and the other, instinctual.

It has been suggested here that the formation of ego comes about through a shift from the id's relation to inner space involving direct awareness concerned with primary needs arising from the components of the mesoderm layer to incorporating a relationship with space outside, which involves the senses. In this shift, the ego grows out of the id (Freud, 1923). This is a natural process as the newborn slowly starts developing the superficial system Pcps-Cs through the use of its senses via its contact with the environment and its parents. It then goes on to slowly develop a complex brain dominated by thoughts and reason. This is in keeping with Fuster's evolutionary perspective.

The protagonist in this development is das Ich, the I who is conscious and whose basic needs have to be modulated to reality or the world outside. The early training of the functions of these basic needs is influenced by the individual's family and cultural norms practised by each family. Our history is related to how we coped with this training, and also how we responded, if, and when, our needs were not met. Traumatic events that occurred particularly during this early part of our history are bound to have left their mark as Freud initially felt in his theory of repression. Later he shied away from the possibility of actual traumatic sexual events influencing future behaviour and replaced it with infantile sexual drives and drive-related fantasies versus memories of abuse (Carveth, 1998). Freud's ideas regarding repression went through various stages but in all of them, repressed material is related to tensions between the contrasting aspects of the agents of the psyche regarding past experiences. "The particular culture in which we live, its values and standards, is crucial in determining which affects we find acceptable... [and] which cannot be adequately discharged" (Greenberg \& Mitchell, 1983: p. 27).

Through correlation, Freud's topographic model seems to fit with the meso hypothesis presented here. There also seems to be a developmental relationship between our anatomical development and the sequence in which the id and the ego unfold. However, the suggestion that we might have a primary perception system which is possibly related to bodily consciousness involving haptic touch, and maybe other vestigial senses, goes beyond Freud's models. It also takes us to a much earlier stage in our development than Freud was considering. From the perspective presented, not only the ego has consciousness, but that the id is also conscious and has awareness, which predates the developing of the thinking mind associated with the prefrontal cortex. This merits further investigation especially as Freud too wondered if the whole of consciousness can be delegated "to the single superficial system Pcps-Cs" (Freud, 1923: p. 8).

Figure 1 outlines the primary and secondary layers, systems and structures that arise out of the meso layer, Freud's model of the mind, and levels of Mind Consciousness. 


\begin{tabular}{|c|c|c|c|c|c|}
\hline & System & Layers & Structures & $\begin{array}{c}\text { Freud's } \\
\text { Model of the } \\
\text { Mind } \\
\end{array}$ & $\begin{array}{c}\text { Levels of } \\
\text { Mind } \\
\text { Consciousness }\end{array}$ \\
\hline $\begin{array}{l}\text { Gastrulation } \\
\text { initiates at } \\
\text { the primitive } \\
\text { streak, } \\
\text { forming an } \\
\text { inner layer } \\
\text { known as: }\end{array}$ & $\begin{array}{l}\text { Secondary } \\
\text { system }\end{array}$ & $\begin{array}{l}\text { Neurulation begins } \\
\text { when the } \\
\text { underlying } \\
\text { notochord induces } \\
\text { the ectoderm layer } \\
\text { above it to } \\
\text { elongate into } \\
\text { columnar neural } \\
\text { plate cells. The } \\
\text { neural plate folds } \\
\text { into the neural } \\
\text { tube, which finally } \\
\text { forms the central } \\
\text { nervous system } \\
\text { including the } \\
\text { neural part of the } \\
\text { brain. }\end{array}$ & $\begin{array}{c}\text { Prefrontal } \\
\text { cortex } \\
5 \text { secondary } \\
\text { brain vesicles } \\
3 \text { brain } \\
\text { vesicles } \\
\text { Spinal nervous } \\
\text { system }\end{array}$ & $\begin{array}{l}\text { Conscious } \\
\text { Mind } \\
\text { Preconscious } \\
\text { Mind }\end{array}$ & $\begin{array}{l}\text { Mind } \\
\text { Consciousness } \\
\text { (involved in } \\
\text { thinking, } \\
\text { perception and } \\
\text { the senses) }\end{array}$ \\
\hline \multirow{2}{*}{$\begin{array}{c}\text { Mesoderm } \\
\text { (Inner space) }\end{array}$} & & & & & \\
\hline & $\begin{array}{l}\text { Primary } \\
\text { system }\end{array}$ & $\begin{array}{l}\text { Mesoderm gives } \\
\text { rise to the } \\
\text { notochord made of } \\
\text { three-dimensional } \\
\text { meso tissue and } \\
\text { other components } \\
\text { of the inner layer. }\end{array}$ & $\begin{array}{l}\text { Structural } \\
\text { components } \\
\text { and major } \\
\text { organs } \\
\text { involved in } \\
\text { bodily } \\
\text { dynamics and } \\
\text { functioning }\end{array}$ & $\begin{array}{l}\text { Unconscious } \\
\text { Mind }\end{array}$ & $\begin{array}{l}\text { Feeling Mind } \\
\text { Consciousness } \\
\text { (bodily based } \\
\text { knowing } \\
\text { involving } \\
\text { feeling and } \\
\text { sensations } \\
\text { possibly } \\
\text { involving } \\
\text { haptic touch } \\
\text { and other } \\
\text { vestigial } \\
\text { senses) }\end{array}$ \\
\hline
\end{tabular}

Figure 1. Possible correlational relationship between systems, layers, structures, levels of the mind consciousness and Freud's model of the mind.

\section{Summing Up}

This article is relevant as it opens a new investigation into our nature which brings in our embryological past, suggests a biological basis for Freud's theories, is based on scientific research findings, questions our identity, and also takes us beyond Freud's ideas and into different levels of consciousness related to our early perception system linked to feeling, bodily knowing, and awareness.

The hypothesis is novel and has many implications, far beyond those mentioned. Our anatomical development tells a story which indicates that mesoderm is primary and via the notochord made of mesoderm tissue, the secondary neur- 
al system is prompted or induced. As Freud's models also involve primary and secondary systems/processes/agents, in this article I have examined how the three theories may be connected through correlation and/or through sequential development by looking at his writings and letting his words speak for themselves.

I have also drawn attention to the fundamental nature of the "entity" of whom Freud is talking by looking at the historical period in which he was writing and his models, taking note that in some instances, there might be errors in the translation of the term psyche.

The perspective presented suggests we might live in a time-bound body with which we are interacting all the time and where the components of the inner mesoderm layer and the concomitant development of the neural system form a process unfolding in time. I have suggested our primary way of knowing maybe a bodily knowing based on feelings, which might involve haptic touch. This idea implies that we could initially be feeling beings. In Freud's model, this feelingbased consciousness may be considered as the perception consciousness system of the id and/or the early bodily ego, whereas the secondary superficial perception consciousness system is related to the external use of the senses by the ego (Freud, 1923). To a large extent, we are not consciously aware of this inner layer, especially traumatic past events linked to our early development. Our capacity to think, associated with the PFC, starts to develop during our first year but only reaches maturity when we are young adults. This suggests that we might have different levels of consciousness; a mind consciousness connected with our thinking ability and our "exterior" perceptual system which relies on our secondary senses, and another level of mind connected with our feeling ability. This is consistent with the theory of "The Theory of the Six Main Levels of Consciousness" (Arka, 2013; Lindhard, 2016, 2018), which proposes that there are more levels than just the two mentioned.

The hypothesis presented possibly has relevance to Whitehead's notion of "prehension" (Whitehead, 1929; Herstein, n.d.) and various body-based healing practices, such as the "felt sense" of Gendlin (2007) and the somatic experiencing method of Levine \& Frederick (1997).

It is also might throw light on somatic-based meditation methods like Prayer of the Heart (Louchakova, 2004, 2007) and the Intuitive Meditation method of Arka (2013). In these methods, "haptic touch" as a primary sense, could be related to intuition as an epistemological way of knowing, connected with feeling (Lindhard, 2020). If a dynamic systems perspective that respects the interrelated way the body unfolds, is used to look at our embryological past, it might also clarify some of the insights brought up in this paper. Possibly, there may also be a relation between the vestigial senses connected with the meso layer and the abilities subsumed under Extra Sensory Perception (ESP), or at least some of them, but that needs further research and investigation.investigation.

The inner "material" body might be where we carry the effects of our unre- 
solved history, desires, and urges that have not been "discharged" due to unresolved emotions. For fear of rejection, or because of contradictions, or tensions between the aspects of the personality as suggested by Freud, we probably learn early on to control these unresolved issues through repression, as reflected in the early development of the ventromedial areas of the prefrontal cortex. Although we have the potential, it is we who develop our secondary perceptual system when we start interacting with other beings and the environment. As our thinking ability develops, it is suggested we form a social ego identity, which is a projection of our surface neural system. It is possible our thinking mind and modern-day materialism have undermined the reality that we live in a body with which we are interacting all the time, but at the same time we are not the body, but neither are we our conscious mind. This brings us back to the concept of the psyche or soul, a term from which many psychologists shy away. Although Freud defined religion as an "illusion", his models open us to a greater spiritual understanding of ourselves.

Freud did not have all the answers, and probably did not go far enough, but he was a true explorer and took the terms soul, consciousness, and mind out of the realm of philosophy and into the realm of scientific discourse based on clinical observation. By suggesting an organic basis for his theories, I hope this paper provides a new perspective from which we can contemplate and make greater sense of some of Freud's explorations, and the nature of ourselves.

\section{Acknowledgements}

I am very grateful to Dr. van der Wal for helping me to see the embryo in a new light and the philosopher Srinivas Arka who helped me understand the nature of heart-based consciousness. I also thank Prof. S. Edwards for his encouragement and timely suggestions regarding the manuscript.

\section{Conflicts of Interest}

The author declares no conflicts of interest regarding the publication of this paper.

\section{References}

APS (2018). Harlow's Classic Studies Revealed the Importance of Maternal Contact. The Association for Psychological Science.

https://www.psychologicalscience.org/publications/observer/obsonline/harlows-classic -studies-revealed-the-importance-of-maternal-contact.html

Arka, S. (2013). Arka Dhyana Intuitive Meditation. An Enlightening Journey into Your Inner Realms Initiated by Your Breath, Sound and Touch. Middlesex, UK: Coppersun Books.

Bettelheim, B. (1984). Freud and Man's Soul. New York: Vintage Books A Division of Random House.

Billig, M. (1999). Freudian Repression: Conversation Creating the Unconscious. UK: Cambridge University Press. https://doi.org/10.1017/CBO9780511490088

Boag, S. (2014). Ego, Drives, and the Dynamics of Internal Objects. Frontiers in Psychol- 
ogy, 5, 666. https://doi.org/10.3389/fpsyg.2014.00666

Boag, S. (2017). Conscious, Preconscious, and Unconscious. In V. Zeigler-Hill, \& T. K. Shackelford (Eds.), Encyclopedia of Personality and Individual Difference. Cham: Springer. https://doi.org/10.1007/978-3-319-28099-8 1370-1

Carveth, D. L. (1998). Psychoanalytic Conceptions of the Passions. In J. O'Neil (Ed.), Freud and the Passions (pp. 25-51). University Park, PA: The Pennsylvania State University.

Champney, T. H. (2016). Essential Clinical Neuroanatomy. UK: Wiley Blackwell.

Coad, J., Pedley, K., \& Dunstall, M. (2011). Anatomy and Physiology for Midwives. London: Churchill Livingstone ( $1^{\text {st }}$ Ed., 2001).

Collins Dictionary (n.d.). Seele. https://www.collinsdictionary.com/dictionary/german-english/seele

Course Hero (n.d.). Topic 02: Neuroanatomy. Course Hero. https://www.coursehero.com/file/233323/braintour/

Damasio, A. R. (1999). The Feeling of What Happens. New York: Harcourt Brace \& Co.

de Bree, K., de Bakker, B., \& Oostra, R.-J. (2018). The Development of the Human Notochord. PLOS ONE, 13, e0205752. https://doi.org/10.1371/journal.pone.0205752

DeSesso, J. M., \& Williams, A. M. (2018). Chap. 10. Periods of Susceptibility: Interspecies. Comparison of Developmental Milestones during Ontogenesis of the Central Nervous System. In W. Slikker Jr., M. G. Paule, \& C. Wang (Eds.), Handbook of Developmental Neurotoxicology (2nd ed., pp. 113-125). Cambridge, MA: Academic Press. https://doi.org/10.1016/B978-0-12-809405-1.00010-9

Diamond, A. (2002). Normal Development of Prefrontal Cortex from Birth to Young Adulthood: Cognitive Functions, Anatomy, and Biochemistry. In D. T. Stuss, \& R. T. Knight (Eds.), Principles of Frontal Lobe Function (pp. 466-503). New York, NY: Oxford University Press. https://doi.org/10.1093/acprof:oso/9780195134971.003.0029

Domenech, P., \& Koechlin, E. (2015). Executive Control and Decision-Making in the Prefrontal Cortex. Current Opinions in Behavioral Science, 1, 101-106.

https://doi.org/10.1016/j.cobeha.2014.10.007

Editors of Encyclopaedia Britannica (n.d.). Mesoderm: Embryology. Encyclopaedia Britannica. https://www.britannica.com/science/mesoderm

Edwards, S. D., \& Edwards, D. J. (2010). Sigmund Freud: Pioneer in Energy Healing. The Journal of Alternative and Complementary Medicine, 16, 219-222. https://doi.org/10.1089/acm.2009.0094

Elshazzly M., Lopez, M. J., Reddy, V., \& Caban, O. (2020). Embryology, Central Nervous System. In StatPearls [Internet]. Treasure Island, FL: StatPearls Publishing. https://www.ncbi.nlm.nih.gov/books/NBK526024/

Freud, S. (1895/1966). Letter 52 from Extracts from the Fleiss Papers. In J. Strachey (Ed.), The Standard Edition of the Complete Works of Sigmund Freud: Vol. 1, 1886-1899: Pre-Psycho-Analytic Publications and Unpublished Drafts (pp. 233-239). London: Hogarth Press.

Freud, S. (1900). The Interpretation of Dreams (Standard Edition, Vol. V). London: Hogarth Press.

Freud, S. (1905). Three Essays on the Theory of Sexuality (Trans. James Strachey). New York: Basic Books.

Freud, S. (1911). Formulations Regarding the Two Principles in Mental Functioning. Collected Papers, Vol. IV. London: Hogarth Press. 
Freud, S. (1914). On the History of the Psycho-Analytic Movement. Standard Edition, Vol. 14, pp. 7-66.

Freud, S. (1915a). The Unconscious. Standard Edition, Vol. 14, pp. 159-204.

Freud, S. (1915b). Instincts and Their Vicissitudes. Collected Papers, IV. London: Hogarth Press, 1925.

Freud, S. (1920). Beyond the Pleasure Principle. Standard Edition, XVIII. London: Hogarth Press.

Freud, S. (1923). The Ego and the Id. Penguin Freud Library (P.F.L.), Vol. 11.

Freud, S. (1925). The Resistance to Psycho-Analysis. Standard Edition, Vol. 19, pp. 213-222.

Freud, S. (1933). New Introductory Lectures on Psychoanalysis. Standard Edition, Vol. 22, pp. 133-157.

Fulkerson, M. (2014). The First Sense: A Philosophical Study of Human Touch. MA: The MIT Press. https://doi.org/10.7551/mitpress/9780262019965.001.0001

Fulkerson, M. (2015). Touch. In Stanford Encyclopedia of Philosophy. https://plato.stanford.edu/entries/touch/

Funahashi, S. (2017). Working Memory in the Prefrontal Cortex. Brain Sciences, 7, 49. https://doi.org/10.3390/brainsci7050049

Fuster, J. J. M. (2013). Chap. 2. Cognitive Functions of the Prefrontal Cortex. In D. T. Stuss, \& R. T. Knight (Eds.), Principles of Frontal Lobe Function (pp. 11-22). Oxford: Oxford University Press. https://doi.org/10.1093/med/9780199837755.003.0002

Fuster, J. M. (2002). Frontal Lobe and Cognitive Development. Journal of Neurocytology, 31, 373-385. https://doi.org/10.1023/A:1024190429920

Fuster, J. M. (2009). Frontal Cortex. In L. R. Squire (Ed.), Encyclopedia of Neuroscience (pp. 905-908). Cambridge, MA: Academic Press.

https://www.sciencedirect.com/science/article/pii/B9780080450469011189?via\%3Dihub https://doi.org/10.1016/B978-008045046-9.01118-9

Garn, S. M. (1952). Physical Growth and Development. American Journal of Physical Anthropology, 10, 169-192. https://doi.org/10.1002/ajpa.1330100215

Gendlin, E. T. (2007). Focusing. New York: Bantam Books.

Gilbert, S. F. (2010). Developmental Biology (9th ed.). Sunderland, MA: Sinauer Associates.

Greenberg, J. R., \& Mitchell, S. A. (1983). Object Relations in Psychoanalytic Theory. Cambridge: Harvard University Press. https://doi.org/10.2307/j.ctvjk2xv6

Grow, W. A. (2018). Chap. 5. Development of the Nervous System. In D. E. Haines, \& G. A. Mihailoff (Eds.), Fundamental Neuroscience for Basic and Clinical Applications (5th ed., pp. 72-90). Amsterdam: Elsevier. https://doi.org/10.1016/B978-0-323-39632-5.00005-0

Hartmann, H. H. (1956). Notes on the Reality Principle. The Psychological Study of the Child, 11, 31-53. https://doi.org/10.1080/00797308.1956.11822781

Herstein, G. L. (n.d.). Alfred North Whitehead (1861-1947). Internet Encyclopedia of Philosophy. https://iep.utm.edu/whitehed/

Hill, M. A. (2020a). Notochord. Embryology.

https://embryology.med.unsw.edu.au/embryology/index.php/Notochord

Hill, M. A. (2020b). Cardiovascular System-Blood Development. Embryology. https://embryology.med.unsw.edu.au/embryology/index.php/Cardiovascular System Blood Development 
Houston, D. W. (2017). Vertebrate Axial Patterning: From Egg to Asymmetry. In F. Pelegri, M. Danilchik, \& A. Sutherland (Eds.), Vertebrate Development. Advances in EXperimental Medicine and Biology (Vol. 953, Pp. 209-306). Cham: Springer. https://doi.org/10.1007/978-3-319-46095-6 6

Human Embryology (n.d). Module Embryonic Disc. Embryology. http://www.embryology.ch/anglais/hdisqueembry/triderm $10 . \mathrm{html}$

Jacobson, E. (2011). Structural Integration: Origins and Development. Journal of Alternative and Complimentary Medicine, 17, 775-780. https://doi.org/10.1089/acm.2011.0001

Jones, J. (n.d.). About the Free Associations Method. Psychoanalysis-Techniques and Practice. http://www.freudfile.org/psychoanalysis/free associations.html

Kardon, G. (2011). Development of the Musculoskeletal System: Meeting the Neighbors. Development, 138, 2855-2859. https://dev.biologists.org/content/138/14/2855 https://doi.org/10.1242/dev.067181

Kierszenbaum, A. L., \& Tres, L. L. (2015). Histology and Cell Biology: An Introduction in Pathology. Philadelphia, PA: Saunders.

Kim, D. H., Xing, T., Yang, Z., Dudek, R., Lu, Q., \& Chen, Y.-H. (2017). Epithelial Mesenchymal Transition in Embryonic Development, Tissue Repair and Cancer: A Comprehensive Overview. Journal of Clinical Medicine, 7, 1. https://doi.org/10.3390/jcm7010001

Levine, P. A., \& Frederick, A. (1997). Awakening the Tiger. Berkeley, CA: North Atlantic Books.

Lindhard, T. (2015). Emotions Including Anger, Bodily Sensations and the "Living Matrix”. The Open Psychology Journal, 8, 3-10. https://doi.org/10.2174/1874350101508010003

Lindhard, T. (2016). Unlocking the Secrets of the Heart through Meditating on the Self. PhD Dissertation, Ghana: Department of Consciousness Studies, University of Professional Studies.

Lindhard, T. (2017). Experiencing Peace through Heart-Based Meditation on the Self. The Open Psychology Journal, 10, 27-40. https://doi.org/10.2174/1874350101710010027

Lindhard, T. (2018). The Theory of Six Main Levels of Consciousness: A Study of the Third Level. Journal of Consciousness Exploration \& Research, 9, 40-61.

Lindhard, T. (2020). Intuition: A Heart-Based Epistemology. Dialogo 2020.

Louchakova, O. (2004). Essence of the Prayer of the Heart. In L. Lozowich (Ed.), Gasping for Air in a Vacuum (pp. 35-50). Prescott, AZ: Holm Press.

Louchakova, O. (2005). Ontopoieses and Union in the Prayer of the Heart: Contributions to Psychotherapy and Learning. In A.-T. Tymeinjecha (Ed.), Logos of Phenomenology and Phenomenology of the Logos. Book Four (Vol. 91, pp. 289-311). Dordrecht: Springer. https://doi.org/10.1007/1-4020-3737-6 21

Louchakova, O. (2007). Spiritual Heart and Direct Knowing in the Prayer of the Heart. Existential Analysis, 18, 81-102.

MacCord, K. (2012). Mesenchyme. The Embryo Project Encyclopedia. https://embryo.asu.edu/pages/mesenchyme

MacCord, K. (2013). Germ Layers. The Embryo Project Encyclopedia. https://embryo.asu.edu/pages/germ-layers

Madison, P. (1956). Freud's Repression Concept: A Survey and Attempted Clarification. International Journal of Psychoanalysis, 37, 75-81. 
Marsh, S. A. (2015). Rolfing: Structural Integration as American Metaphysical Religiosity. PhD Dissertation, Boulder, CO: Department of Religious Studies, University of Colorado.

McCraty, R. (2003). The Energetic Heart: Bioelectromagnetic Interactions within and between People. Neuropsychotherapist, 6, 22-43.

Miller, S. G. (2016). Do Fetuses Feel Pain? What the Science Says. Live Science. https://www.livescience.com/54774-fetal-pain-anesthesia.html

Moscoso, G. (2009). Early Embryonic Development of the Brain. In M. Levene, \& F. Chervenak (Eds.), Fetal and Neonatal Neurology and Neurosurgery (pp. 13-21). Atlanta, GA: Elsevier Health Sciences.

Muhr, J., \& Ackerman, K. M. (2020). Embryology, Gastrulation. In StatPearls [Internet]. Treasure Island, FL: StatPearls Publishing. https://www.ncbi.nlm.nih.gov/books/NBK554394/

Mulkey, S. B., \& du Plessis, A. J. (2019). Autonomic Nervous System Development and its Impact on Neuropsychiatric Outcome. Pediatric Research, 85, 120-126. https://doi.org/10.1038/s41390-018-0155-0

Murray, C. J. (2004). Encyclopedia of the Romantic Era, 1760-1850. New York: Taylor \& Francis.

Nummenmaa, L., Glerean, E., Hari, R., \& Hietanen, J. K. (2013). Bodily Maps of Emotions. Proceedings of the National Academy of Sciences of the United States of Amer ica, 111, 646-651. https://doi.org/10.1073/pnas.1321664111

Openmd (n.d.). Mesoderm. Openmd. https://openmd.com/define/mesoderm

OpenStax (n.d.). 13.1. Embryologic Perspective. Anatomy and Physiology. https://openstax.org/books/anatomy-and-physiology/pages/13-1-the-embryologic-pers pective

Pearsall, P., Schwartz, G. E., \& Russek, L. G. (2005). Organ Transplants and Cellular Memories. Nexus Magazine, 12. http://www.paulpearsall.com/info/press/3.html

Porges, S. W. (2001). The Polyvagal Theory: Phylogenetic Substrates of a Social Nervous System. International Journal of Psychophysiology, 42, 123-146. https://doi.org/10.1016/S0167-8760(01)00162-3

Porges, S. W. (2009). The Polyvagal Theory: New Insights into Adaptive Reactions of the Autonomic Nervous System. Cleveland Clinic Journal of Medicine, 76, S86-S90. https://doi.org/10.3949/ccjm.76.s2.17

Pribram, K. H. (2005). Freud's Project for a Scientific Psychology in the 21st Century. Semantic Scholar, 169-177.

https://www.semanticscholar.org/paper/Freud's-project-for-a-scientific-psychology-inthe-Pribram/3ff497ef6ca978b2a531c504a31797af116efac7 https://doi.org/10.1553/3-7001-3386-3s169

Pribram, K. H., \& Melges, F. T. (1969). Psychophysiological Basis of Emotion. In. J. Vinken, \& G. W. Bruyn (Eds.), Handbook of Clinical Neurology (Vol. 3, pp. 316-341). Amsterdam: North-Holland Publishing Company. http://karlpribram.com/wp-content/uploads/pdf/theory/T-033.pdf

Richtsmeier, J. T. (1999). Development of the Heart. Getahead. https://www.getahead.la.psu.edu/documents/HEARTDEV.LEC.doc

Schoenwolf, G., Bley, S., Brauer, P., \& Francis-West, P. (2015). Larsen's Human Embry$\operatorname{ology}(5$ th ed.). Philadelphia, PA: Elsevier.

Segalerba, G. (2019). The Drama of the Human Condition. Notes on the Causes and Origins of Evil in Plato's Republic. Revue Roumaine de Philosophie, 63, 19-35. 
Skirry, J. (n.d.). René Descartes: The Mind Body Distinction. Internet Encyclopedia of Philosophy. https://www.iep.utm.edu/descmind/

Skofield, J. (2012). Mindshock: Transplanting Memories. (Video File) https://www.youtube.com/watch?v=GADSbc2AI8I

Stemple, D. L. (2005). Structure and Function of the Notochord: An Essential Organ for Chordate. Development, 132, 2503-2512. https://doi.org/10.1242/dev.01812

Tran The, J., Magistretti, P., \& Ansermet, F. (2018). The Epistemological Foundations of Freud's Energetics Model. Frontiers in Psychology, 9, 1861. https://doi.org/10.3389/fpsyg.2018.01861

Tulving, E. (1972). Episodic and Semantic Memory. In E. Tulving, \& W. Donaldson (Eds.), Organization of Memory (pp. 590-600). New York: Academic Press.

Van der Kolk, B. A. (1994). The Body Keeps the Score: Memory and the Evolving Psychobiology of Posttraumatic Stress. Harvard Review Psychiatry, 1, 253-265. https://doi.org/10.3109/10673229409017088

Van der Wal, J. (2003/2014). Dynamic Morphology and Embryology. In G. van der Bie, \& M. Huber (Eds.), Foundations of Anthroposophical Medicine (pp. 1-53). Edinburgh: Floris Books. https://www.embryo.nl/upload/documents/artikelen-embryosofie/Dynamic\%20Morph ology\%20and\%20Embryology\%202014\%20A4\%20EN\%20chapter.pdf

Villavicencio, K. L. (2010). Chap. 21. Fetal Arrhythmias. In J. A. Drose (Ed.), Fetal Echocardiography. St. Louis: Saunders.

Whitehead, A. N. (1929). Process and Reality: An Essay in Cosmology. New York: Free Press. (1979 corrected edition, edited by David Ray Griffin and Donald W. Sherburne)

Wilson, R. A., \& Foglia, L. (2015). Embodied Cognition. Stanford Encyclopedia of Philosophy. https://plato.stanford.edu/entries/embodied-cognition/ 